\title{
Usabilidade: um estudo aplicado ao Visualizador da Infraestrutura de Dados Espaciais do Brasil (VINDE)
}

\author{
Valéria Oliveira Henrique de Araújo* \\ María Ester Gonzalez Campos** \\ Raquel Aparecida Abrahão Costa e Oliveira**
}

Recebido 12 de marzo de 2017; aceito 4 de julho de 2017

\begin{abstract}
The present research proposes the assessment of the Data Viewer of the National Spatial Data Infrastructure (VINDE) according to the usability parameters (effectiveness, efficiency and satisfaction). Neither in the study, planning or implementation phase (requirements of specification, design and prototyping, development and customization), nor in the years that followed (operational portal) were done any specific study or usability test.

Through a selfdeveloped methodology comprising a performance test in a predetermined time, as well as a subjective assessment questionnaire, the System Usability Scale (SUS), applied to a group of 20 geo-experts. To validate the methodology, a pilot test and a later performance test on VINDE have been carried out.

The results and analyses evince the viewer is not easy to browse even for a group of geoinformation experts. It still has a number of issues to be improved concerning the organization, naming and structuring of its themes and layers, as well as enhancements in its tools and general layout for should be improved to satisfactorily meet the demands of its users.

Key words: Spatial Data Infrastructure, Usability, Geoportal, Geospatial Information, Map Viewer.
\end{abstract}

* Instituto Militar de Engenharia (IME) - Instituto Brasileiro de Geografía de Estatística (IBGE), Brasil, e-mail: valeria.araujo@ibge.gov.br

** Universidad de Concepción, Chile, correo electrónico: mariaesgonzalez@udec.cl

****Instituto Militar de Engenharia (IME), Brasil, e-mail: raquel.oliveira@ime.eb.br 


\section{Resumen}

La investigación presentada propone evaluar el Visualizador de Mapas de la Infraestructura de Datos Espaciales (VINDE) según los parámetros de la usabilidad (eficacia, eficiencia y satisfacción). En la fase de estudio, planificación e implementación (especificaciones de requerimientos, diseño y prototipo, desarrollo y personalización), se realizó en un estudio específico a través de una prueba de usabilidad.

A través de una metodología propia, se diseñó y aplicó una prueba de desempeño para ser realizada en un tiempo determinado. Además, se aplicó el cuestionario de evaluación subjetiva System Usability Scale (SUS), a un grupo de veinte geoespecialistas. Para validar esta metodología se realizó una prueba piloto y posteriormente una prueba de usabilidad en VINDE. Los resultados y análisis evidencian que el visualizador no es fácilmente navegable ni para un grupo de expertos en geoinformación, y que varios puntos aún deben ser mejorados en relación a la organización, nombres y estructuración de sus temas y capas, además de la necesidad de mejorar sus herramientas y el diseño de una forma general para que pueda atender de forma satisfactoria a sus usuarios.

Palabras clave: Infraestructura de Datos Espaciales, Usabilidad, Geoportal, Información geoespacial, Visualizador de mapas.

\section{Resumo}

A pesquisa apresentada propõe avaliar o Visualizador de Dados da Infraestrutura Nacional de Dados Espaciais (VINDE) segundo os parâmetros da usabilidade (eficácia, eficiência e satisfação). Nem na fase de estudos, planejamento ou implementação (especificação de requerimentos, design e prototipagem, desenvolvimento e customização), nem nos anos que se seguiram (com o portal operativo) foi realizado nenhum estudo específico ou teste de usabilidade.

Através de metodologia própria, foi construído e aplicado um teste de desempenho para ser realizado em um tempo predeterminado. Além disso, foi aplicado um questionário de avaliação subjetiva, o System Usability Scale (SUS), a um grupo de vinte geoespecialistas. Para validar essa metodologia foi realizado um teste piloto e, posteriormente, uma prova de desempenho no VINDE. Os resultados e análises evidenciam que o visualizador não é facilmente navegável nem mesmo para um grupo de especialistas em geoinformação, e que vários pontos ainda devem ser melhorados em relação à organização, nomeação e estruturação de seus temas e camadas, além da necessidade de aprimoramentos em suas ferramentas e layout de uma forma geral para que possa atender de forma satisfatória seus usuários.

Palavras chave: Infraestrutura de Dados Espaciais, Usabilidade, Geoportal, Informação Geoespacial, Visualizador de mapas. 


\section{Introdução}

O geoportal da Infraestrutura Nacional de Dados (INDE) do Brasil, na época do lançamento em 2010, tinha como visualizador de mapas o i3geo, ${ }^{1}$ disponível no Portal do Software Público. Em 2012, o Instituto Brasileiro de Geografia e Estatística (IBGE) identificou a necessidade de um visualizador mais amigável e, num esforço interno disponibilizou mais uma ferramenta de visualização de mapas da INDE que se denominou VINDE. Nem na fase de estudos, nem no planejamento ou ainda na implementação (especificações de requerimentos, design e prototipagem, desenvolvimento e customização), nem nos anos que se seguiram (com o portal operativo) foi realizado nenhum estudo específico ou teste de usabilidade. Também não foi realizado qualquer tipo de estudo ou pesquisa de satisfação com usuários após sua implantação.

A fim de justificar a importância desta pesquisa, por meio dos relatórios do Google Analytics da página do VINDE² obteve-se a informação de que no período de Junho de 2012 (lançamento do VINDE) a Dezembro de 2015 (corte para a pesquisa), 55.027 usuários acessaram o visualizador, uma média de 1775 usuários/mês, e sempre com uma taxa de rejeição bastante alta, média de 80,10\% (Figura 1). Os critérios para obtenção dessa taxa de rejeição estão disponíveis em: $<$ http://support.google.com/analytics>. Apenas 38,3\% são visitantes reincidentes, ou seja, a cada dois usuários que acessam o site, menos de um regressa novamente e, a duração média da sessão é de $1 \mathrm{~m} 57 \mathrm{seg}$, ou seja, muito pouco para qualquer tipo de carregamento, visualização e/ou análise. Ver gráfico na Figura 1.

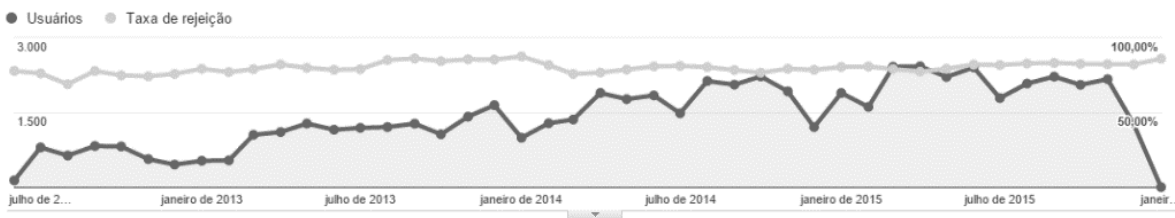

Figura 1. Acessos ao VINDE - número de usuários/mês e taxa de rejeição.

Fonte: Google Analytics <https://www.visualizador.inde.gov.br>.

Em função dos dados apresentados tornou-se evidente a importância de se promover estudos de usabilidade no geoportal do VINDE. Para isso, pensou-se numa metodologia baseada em tarefas que permitiu se obter resultados de eficiência e eficácia, dois dos parâmetros da usabilidade segundo a ISO 9241-11:1998. O terceiro parâmetro correspondente a satisfação se obteve a partir da adaptação e aplicação

1 Disponível em <https://softwarepublico.gov.br/social/i3geo/>.

2 Disponível em $<$ https://www.visualizador.inde.gov.br>. 
do questionário System Usability Scale (SUS). A partir da aplicação da metodologia a um grupo de 20 usuários geoespecialistas, se espera que os resultados obtidos possam servir de referência a mudanças e melhorias e também para outros estudos e pesquisas posteriores.

\section{Usabilidade e geoportais}

Dada a evolução das Tecnologias de Informação Geográfica (TIG) em relação à representação e à visualização dos dados através da web, o fenômeno dos geoportais se destacou, contando atualmente com múltiplas opções e ferramentas à disposição dos usuários (Sanxiao et al., 2012).

Os objetivos dos geoportais devem servir de referência durante todo o processo de construção ou reestruturação do mesmo e a preocupação em mantê-lo sempre atual deve ser uma constante. Os geoportais IDE oferecem a cartografia através do visualizador de mapas, uma aplicação web para visualização e consulta de IG onde é desejável que façam uso dos padrões OGC. Os usuários esperam de um geoportal o melhor resultado em relação ao motivo de sua visita (efetividade), gastando o menor número de recursos (eficiência) e, ainda, que a experiência lhe seja agradável (satisfação). E, são estas três características que a International Organization for Standardization (ISO), utiliza para definir usabilidade. Segundo a ISO, usabilidade é a medida com a qual se avalia se um produto pode ser utilizado por determinados usuários para alcançar objetivos específicos com efetividade, eficiência e satisfação em um contexto de uso específico (ISO 9241-11:1998).

Jakob Nielsen e Hoa Loranger (2006) conceituam usabilidade como um atributo de qualidade relacionado à facilidade do uso de algo. Mais especificamente, referese à rapidez com que os usuários podem aprender a usar alguma coisa, a eficiência deles ao usá-la, o quanto lembram daquilo, seu grau de propensão a erros e, o quanto gostam de utilizá-la. Para Krug (2006), autor do livro "Não me faça pensar" (Título original em inglês: Don't make me think), uma abordagem de bom senso à usabilidade web significa que para se considerar que algo funciona bem, uma pessoa com capacidade e experiência média (ou mesmo abaixo da média) deve usá-lo seja um website, um avião de combate ou porta giratória - para a finalidade pretendida sem sentir-se irremediavelmente frustrado.

\section{Geoportal INDE}

A IDE do Brasil, a Infraestrutura Nacional de Dados Espaciais (INDE), foi instituída pelo Decreto Federal no 6.666, de 27 de novembro de 2008, e seu lançamento oficial aconteceu em abril de 2010. A INDE foi implantada sob a coordenação da Comissão Nacional de Cartografia (CONCAR), órgão colegiado do Ministério do 
Planejamento, Desenvolvimento e Gestão (MPDG), e tem como objetivos: ordenar a geração, o armazenamento, o acesso, o compartilhamento, a disseminação e o uso dos dados geoespaciais das mais diversas origens. Além disso, promove a utilização e produção dos dados geoespaciais, dos padrões e normas homologados pela CONCAR, evitando a duplicidade de ações e o desperdício de recursos na obtenção dessas informações, principalmente pelos órgãos da administração pública a través de seus metadados. O projeto da INDE foi estruturado através de um Plano de Ação, construído de forma colaborativa com a participação de diversos atores institucionais (CONCAR, 2010).

A INDE está fundamentada em cinco pilares ou componentes: dados, pessoas, instituições, tecnologia e, normas e padrões. Considerando-se todos esses componentes e elementos funcionando e interagindo conforme as normas cabe-se destacar que as IDE se fazem visíveis através dos geoportais acessados pela Internet.

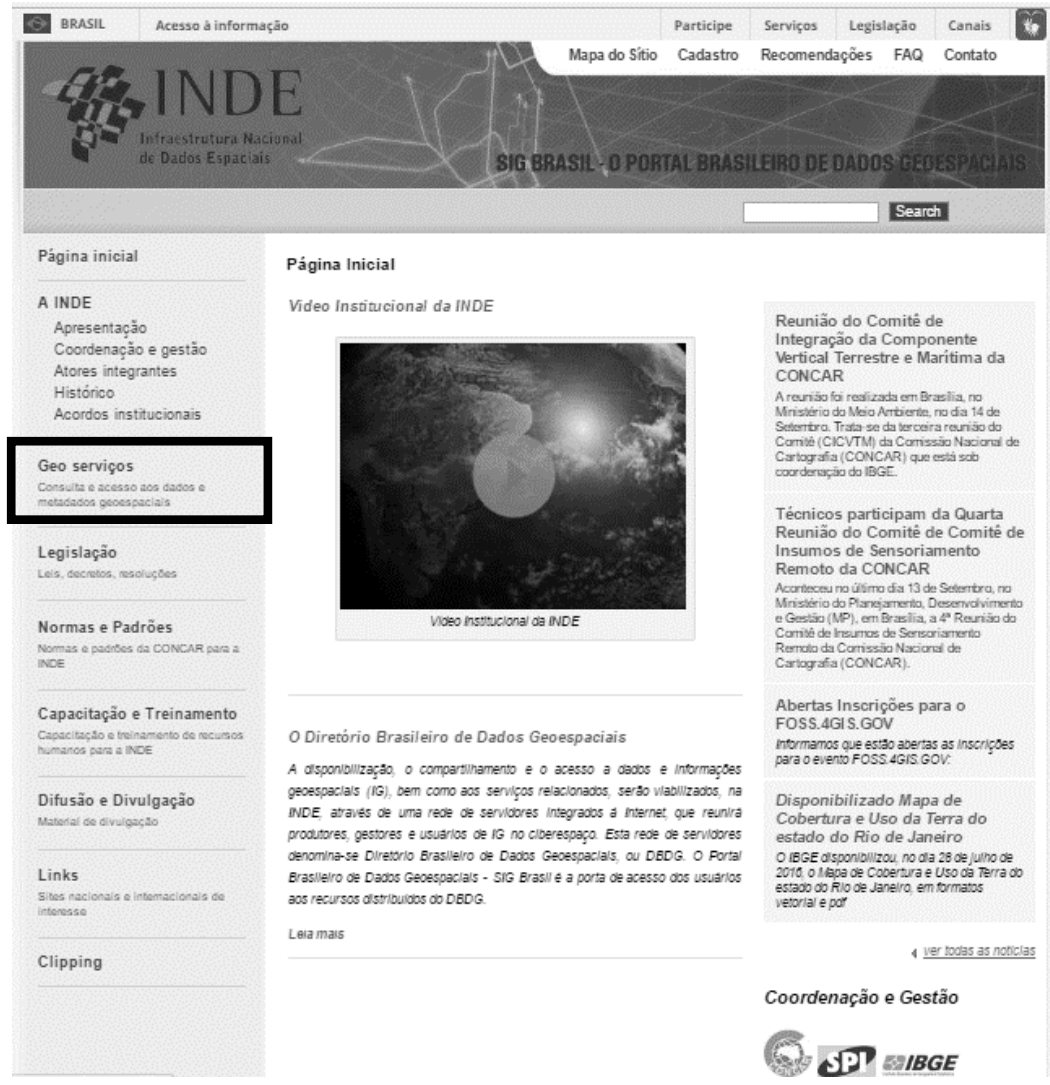

Figura 2. Geoportal da INDE com destaque para o acesso em Geosserviços.

Fonte: <www.inde.gov.br>. 
O geoportal da INDE (Figura 2) oferece Catálogo de Metadados, Catálogo de Geosserviços e, Visualizador de Dados, no caso, VINDE, objeto desta pesquisa. O acesso se dá através da página principal, link de geosserviços, conforme destacado na Figura 2. Os dados poderão ser acessados através do visualizador (VINDE), e os metadados e serviços, através de seus respectivos catálogos. A disponibilização de dados e metadados geoespaciais acontece através de servidores de dados próprios das instituições que os produzem e armazenam ou servidores gerenciados diretamente pelo Diretório Brasileiro de Dados Geoespaciais (DBDG) cuja responsabilidade por decreto é do Instituto Brasileiro de Geografia e Estatística (IBGE).

O VINDE (Figura 3) foi concebido e implementado fazendo uso de ferramentas e funções básicas, como zoom, inserção e exclusão de camadas, etc. Além do acesso via geoportal (www.inde.gov.br $=>$ geosserviços $=>$ visualizadores $=>$ VINDE), o visualizador também pode ser acessado por meio da digitação direta do seguinte endereço eletrônico: <http://www.visualizador.inde.gov.br/>. Os dados disponíveis podem ser acessados através das opções: “Busca”, “Tema” (atualmente são encontrados 39 temas principais, com subdivisões de temas derivados destes) e "Instituição”.

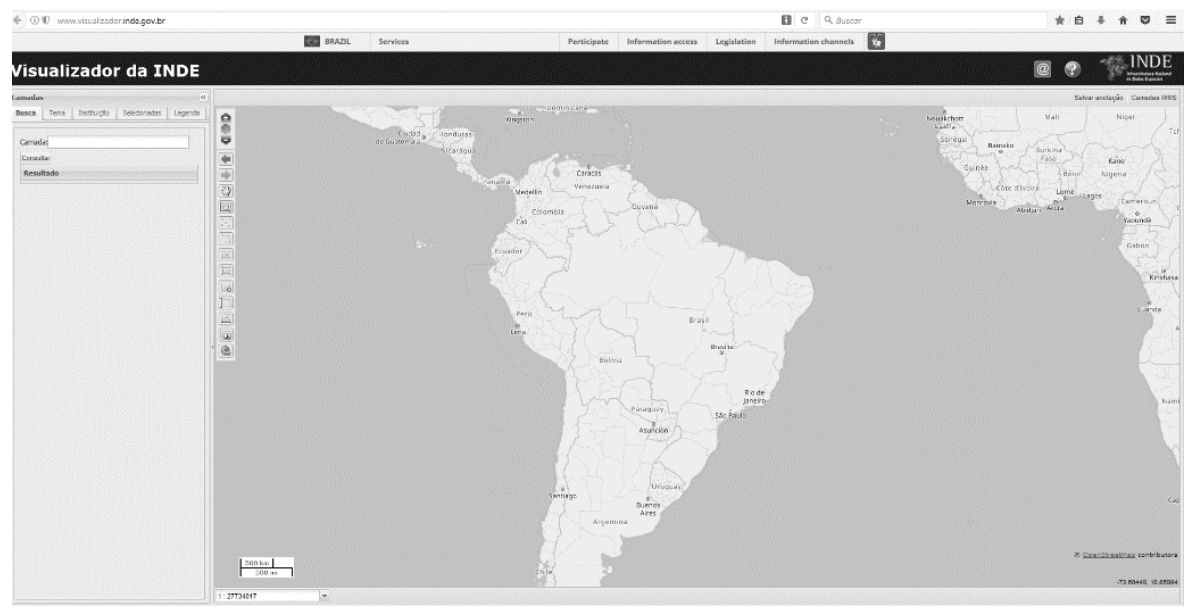

Figura 3. VINDE, página principal.

Fonte: <www.inde.gov.br>.

No caso desta pesquisa, o objetivo geral era avaliar a usabilidade do visualizador do Geoportal da Infraestrutura Nacional de Dados Geoespaciais (VINDE) e, os objetivos específicos foram: 
1. Identificar as principais metodologias para avaliação de usabilidade de geoportais;

2. Elaborar uma metodologia para avaliar a usabilidade do visualizador de mapas do geoportal da INDE;

3. Validar esta metodologia através de uma prova piloto;

4. Definir uma prova para avaliar a usabilidade;

5. Aplicar a metodologia previamente definida a um grupo de usuários que respondam a um determinado perfil.

Após os testes os usuários deveriam esperar o melhor resultado em relação ao motivo de sua visita (efetividade), gastando o menor número de recursos (eficiência) e, ainda, que a experiência fosse agradável (satisfação). E, são estas três características que a International Organization for Standardization (ISO), utiliza para definir usabilidade.

\section{Método proposto}

Para a metodologia proposta se tomou como referência o Geotest, teste desenvolvido em 2012, através da parceria da empresa Future Position X, o National Land Survey of Sweden (NLS) e a University of Gävle, todos localizados na Suécia. A prova foi realizada no Geoportal IDE da Suécia (Geodataportalen) ${ }^{3}$ e contou com 14 funcionários de distintos serviços públicos com mais de dois anos de experiência em Sistema de Informações Geográficas (SIG). Do total de usuários testados, oito já haviam usado previamente um geoportal; sete tinham menos de quarenta anos e dez tinham mais de seis anos de experiência em SIG.

Posteriormente, em 2015, o Proyecto de Usabilidade IDE do IPGH (2015), desenvolveu metodologia para avaliação de usabilidade de geoportais IDE e aplicou a mesma aos geoportais dos países participantes do projeto (Chile, Argentina, Equador, Uruguai e Brasil). A média de satisfação dos usuários ao utilizarem o geoportal foi inferior a $50 \%$.

Em relação a esta pesquisa para avaliar a usabilidade do VINDE através de medidas de eficácia, eficiência e satisfação, o método proposto consistiu na aplicação de uma prova de usabilidade composta de testes distintos aplicados a usuários que utilizaram o geoportal do VINDE. Para isso, seguiu-se o seguinte roteiro (Araújo e Gonzalez, 2015): aplicação de prova baseada em tarefas para medir eficiência e eficácia, aplicação do questionário SUS para medir a satisfação e aplicação de um questionário sobre o perfil de usuários para se conhecer maiores detalhes sobre os usuários. 
A prova baseada em tarefas contou com 13 (treze) atividades com tempo préestabelecidos para serem executadas. Tomou-se por base as pesquisas já citadas anteriormente e feitas as devidas adequações para o caso do VINDE. As atividades e os tempos para executá-las são apresentados na Tabela 1.

Tabela 1

Tarefas para a avaliação da usabilidade do geoportal da INDE

\begin{tabular}{|c|c|c|}
\hline $\begin{array}{c}\text { Ordem } \\
\text { sequencial }\end{array}$ & Tarefa & $\begin{array}{c}\text { Tempo } \\
\text { (minutos) }\end{array}$ \\
\hline 1 & $\begin{array}{l}\text { Entrar no website da Infraestrutura de Dados Espaciais do } \\
\text { Brasil }\end{array}$ & 2 \\
\hline 2 & Procurar e abrir o visualizador de mapas VINDE & 2 \\
\hline 3 & Buscar e ativar a camada de Rede Viária Nacional (Rodovias) & 3 \\
\hline 4 & $\begin{array}{l}\text { Visualizar um mapa que mostre as seguintes camadas: limites } \\
\text { administrativos (Estado OU Município) e localização das } \\
\text { cidades }\end{array}$ & 5 \\
\hline 5 & Visualizar a legenda de uma das duas camadas anteriores & 2 \\
\hline 6 & $\begin{array}{l}\text { Realizar um “zoom +”e identificar a escala de visualização na } \\
\text { tela }\end{array}$ & 2 \\
\hline 7 & Medir uma distância A-B & 2 \\
\hline 8 & $\begin{array}{l}\text { Aproveitando uma das camadas já abertas anteriormente, } \\
\text { visualizar a informação associada à mesma (atributos). }\end{array}$ & 2 \\
\hline 9 & $\begin{array}{l}\text { Agregar ao visualizador da IDE um serviço de mapas WMS } \\
\text { (Web Map Service). Sugere-se a consulta a um servidor } \\
\text { Geoserver para obtenção do link relativo ao serviço a ser } \\
\text { consumido. (Exemplo: http://www.geoservicos.inde.gov.br/ } \\
\text { =>Layer Preview => Open Layer => escolha um layer de sua } \\
\text { preferência) }\end{array}$ & 5 \\
\hline 10 & $\begin{array}{l}\text { Salvar ou imprimir o mapa atual que se apresenta na tela, } \\
\text { utilizando alguma das seguintes opções que se encontram } \\
\text { disponíveis nos visualizadores: “imprimir mapa” ou "salvar } \\
\text { imagem” ou “salvar link” para recuperar ou compartilhar o } \\
\text { mapa }\end{array}$ & 2 \\
\hline 11 & Visualizar os metadados de uma camada qualquer & 2 \\
\hline 12 & $\begin{array}{l}\text { Aproveitando as camadas que já estão carregadas em tela, } \\
\text { reordene as mesmas aleatoriamente }\end{array}$ & 2 \\
\hline 13 & $\begin{array}{l}\text { Aproveitando as camadas que já estão carregadas em tela, } \\
\text { exercite a função de transparência das camadas }\end{array}$ & 2 \\
\hline
\end{tabular}

Fonte: Elaboração própria. 


\section{Questionário SUS}

Trata-se de um teste de avaliação subjetiva (através de questionário) desenvolvido em 1986 por John Brooke no laboratório da Digital Equipment Corporation, no Reino Unido. O SUS é uma escala Likert $^{4}$ construída mediante a identificação de eventos que conduzem a expressões extremas da atitude do participante. Foram selecionadas as perguntas finais dentre cinquenta itens potenciais. Estas perguntas cobrem uma variedade de aspectos, como a facilidade de uso do sistema, a necessidade de apoio, a formação, a complexidade, e, portanto, têm um alto nível de validade para se medir a facilidade de uso de um sistema (Brooke, 1996).

O SUS é um sistema independente e tem sido testado em computadores, programas, websites, telefones celulares e outros (Sauro, 2011). Trata-se de um questionário de dez afirmações, sendo cinco de caráter positivo e cinco de caráter negativo, que avaliam a satisfação do usuário. Esta técnica permite que se obtenha um valor percentual de nível de satisfação geral do usuário.

As perguntas são qualificadas numa escala de 1 a 5 , sendo 1 completamente em desacordo e 5 completamente de acordo, e são estabelecidos pesos específicos às respostas dadas para as perguntas pares e para as ímpares.

Para esta pesquisa, a estrutura original do questionário de Brooke (1996) com as dez afirmativas foi mantida com algumas poucas adequações para o caso do VINDE. A Tabela 2 mostra o questionário traduzido ao português e adaptado ao caso do VINDE.

Tabela 2

Afirmativas SUS traduzidas ao português e adaptadas ao caso do VINDE

\begin{tabular}{cl}
\hline 1 & Creio que gostaria de utilizar o geoportal do VINDE frequentemente \\
2 & Achei o visualizador desnecessariamente complexo \\
3 & Penso que o geoportal VINDE foi fácil de usar \\
4 & Creio que necessitaria do apoio de um técnico para utililizar o geoportal \\
5 & Achei que as diferentes funções do geoportal VINDE foram bem integradas \\
6 & Penso que havia muitas inconsistências no geoportal VINDE \\
7 & Imagino que a maioria das pessoas aprenderiam a usar rapidamente o geoportal \\
& VINDE \\
8 & Achei o geoportal muito difícil de usar \\
9 & Me senti muito confortável usando o geoportal VINDE \\
10 & Preciso aprender muitas coisas antes de utilizar o geoportal \\
\hline
\end{tabular}

Fonte: $\quad$ Adaptado de Brooke, 1996.

4 Disponível em <https://pt.surveymonkey.com/mp/likert-scale/>. 
Se realizou uma prova piloto com 12 usuários com a finalidade de validar a metodologia previamente definida e, sendo realizados os correspondentes ajustes. Essa prova piloto foi documentada pela autora em artigo encaminhado ao International Cartographic Conference em 2015 (Araujo et al., 2015).

\section{Participantes y procedimentos}

A prova de usabilidade foi aplicada a usuários que respondiam a algumas das seguintes características: utilizavam dados e informação geoespacial, trabalhavam em instituições relacionadas com IG, ou fossem estudantes ou docentes de carreiras relacionadas com IG.

Nielsen (2012), em seu artigo “How Many Test Users in a Usability Study?”, é categórico ao afirmar que o número ideal de usuários em testes de usabilidade é cinco. Segundo o autor, com esse número é possível encontrar quase tantos problemas de usabilidade como nos testes com muitos participantes. Não importa se você testa websites, intranets, aplicativos para computador ou aplicativos móveis. Com cinco participantes, você quase sempre chega perto da relação custo-benefício máxima de testes com usuários. A grande maioria das pesquisas com usuários deve ser qualitativa e destinada a recolher ideias para conduzir o seu projeto, e não composta de números para impressionar as pessoas.

Como, para o caso da pesquisa, não seria possível dimensionar o tamanho do universo da amostra uma vez que "geoespecialistas" podem ser das mais variadas formações e procedência, optou-se em considerar os estudos específicos de tamanho de amostras para testes de usabilidade publicados por autores consagrados como Nielsen, descrito acima. Diante disso, foram convidados 20 geoespecialistas. As procedências foram do setor público, do setor privado e da academia (professores e alunos).

Para o teste de execução de tarefas foi utilizado um único equipamento (laptop da autora) onde procedeu-se à instalação do software de gravação de tela e áudio CamStudio e do cronômetro virtual Task Timer (Google). Ambas as ferramentas foram escolhidas a partir das referências do Manual de Procedimentos do Proyecto de Usabilidade IDE do IPGH (2015). O CamStudio é um software livre, de fácil instalação e manuseio e de bons resultados em relação ao que se destina. A instalação foi configurada para que o software procedesse à gravação de tela e áudio durante a execução da prova. O cronômetro virtual Task Timer foi configurado especialmente para o teste com a inserção das 13 atividades e os tempos máximos estabelecidos para execução de cada uma. Foram reservadas salas devidamente preparadas nas Unidades do IBGE e no Laboratório de Cartografia do IME.

As tarefas consistiam em: abrir o geoportal, buscar camadas de informações distintas, carregar WMS (Web Map Service), agregar WMS mediante sua URL (Uniform Resource Locator, em português Localizador Uniforme de Recursos) e 
fazer operações com as ferramentas do visualizador com tempos limites para a execução de cada tarefa. A Tabela 1 apresenta cada uma das atividades e os tempos máximos para execução, ressaltando-se que as tarefas 11, 12 e 13 são bastante específicas do VINDE e as demais mais gerais e facilmente adaptáveis a outros geoportais IDE.

\section{Resultados e Análises}

Os resultados e análises foram feitas em quatro partes distintas (Araújo, 2016):

- Características do perfil da amostra e os resultados obtidos a partir da aplicação do questionário de perfil de usuário;

- Registro das observações realizadas em tempo real durante a prova, assim como as observações feitas a partir das gravações de telas e áudios;

- Resultados obtidos no teste de usabilidade baseado em tarefas;

- Resultados do questionário SUS.

Na prova baseada em tarefas mediu-se a eficácia (cujo objetivo era terminar a tarefa) e eficiência (relação com o recurso empregado, neste caso o tempo, utilizado para cumprir o objetivo). No questionário SUS mediu-se a satisfação.

As características da amostra, por sua vez, basearam-se nos resultados obtidos do questionário de perfil de usuários. Nas tabelas 3 e 4 a seguir se apresentam as informações gerais da amostra: idade e titulação mais alta que possuem os participantes da prova.

Entre as titulações dos participantes se encontram as seguintes especialidades: Engenharia Cartográfica, Geografia, Engenharia de Software, Análise Ambiental e Gestão do Território, Geomática, Ciência Atmosférica em Engenharia, Geologia, Geoinformática e Engenharia de Sistemas.

Tabela 3 e 4

Faixa de idade/número usuários e Titulação e percentual de usuários

\begin{tabular}{|c|c|c|c|}
\hline \multirow{2}{*}{$\begin{array}{c}\text { Faixa de } \\
\text { Idade }\end{array}$} & \multirow[b]{2}{*}{$\%$} & Titulação & $\%$ \\
\hline & & Doutorado & 20 \\
\hline $20-30$ & 20 & Pós-graduação(Mestrado, Espec.) & 45 \\
\hline $31-40$ & 30 & Graduação (Licenciatura, Engenharia) & 30 \\
\hline $41-50$ & 10 & Bacharelado(estudantes universitários) & 5 \\
\hline $51-60$ & 30 & Total & 100 \\
\hline+60 & 10 & & \\
\hline
\end{tabular}

Fonte: Elaboração própria. 
A partir da revisão de cada um dos vídeos, foram identificadas as tarefas terminadas corretamente (TC) e as tarefas não terminadas ou terminadas incorretamente (TI) assim como os tempos totais que cada usuário realizou a prova. O tempo médio que os 20 (vinte) usuários levaram para realizar a prova, 17' 27”' dentro dos 33' permitidos (Tabela 5).

Tabela 5

Resultados do teste de desempenho

\begin{tabular}{lrrl}
\hline \multicolumn{1}{c}{ Usuário } & \multicolumn{1}{c}{ TC } & TI & Tempo \\
\hline Usuário 1 & 7 & 6 & $27: 29$ \\
Usuário 2 & 13 & 0 & $09: 59$ \\
Usuário 3 & 11 & 2 & $15: 04$ \\
Usuário 4 & 9 & 4 & $21: 50$ \\
Usuário 5 & 8 & 5 & $25: 18$ \\
Usuário 6 & 11 & 2 & $23: 03$ \\
Usuário 7 & 6 & 7 & $13: 58$ \\
Usuário 8 & 8 & 5 & $17: 19$ \\
Usuário 9 & 13 & 0 & $12: 53$ \\
Usuário 10 & 13 & 0 & $13: 05$ \\
Usuário 11 & 12 & 1 & $16: 01$ \\
Usuário 12 & 10 & 3 & $16: 46$ \\
Usuário 13 & 8 & 5 & $23: 32$ \\
Usuário 14 & 13 & 0 & $15: 29$ \\
Usuário 15 & 10 & 3 & $23: 58$ \\
Usuário 16 & 11 & 2 & $14: 43$ \\
Usuário 17 & 12 & 1 & $14: 50$ \\
Usuário 18 & 12 & 1 & $15: 36$ \\
Usuário 19 & 11 & 2 & $15: 48$ \\
Usuário 20 & 12 & 1 & $12: 13$ \\
\hline Tempo médio total & & & $17: 27$ \\
\hline Tempo total máximo possível & & $33: 00$ \\
\hline
\end{tabular}

Fonte: elaboração própria.

Sendo:

TC = número de tarefas concluídas corretamente

$\mathrm{TI}$ = número de tarefas incorretas ou incompletas

Tempo = tempo que cada usuário levou para completar a prova 
Baseado em anotações e em análises das gravações de telas e dos áudios gravados (com a autorização dos usuários), foram feitos registros dos caminhos percorridos por cada um dos usuários durante o teste de desempenho. São destacados a seguir os principais pontos ressaltados pela maioria dos usuários:

Tarefa 2 - Acesso ao VINDE ("Procurar e abrir o visualizador de mapas VINDE”). Os usuários tiveram dificuldades em achar o caminho para o VINDE. O link na página principal, que se dá por meio da opção “Geosserviços”, não foi visualizado e entendido como porta de entrada imediata pela maioria. Uma outra opção seria a digitação no browser da URL do VINDE (visualizador.inde.gov.br) mas, somente 2 usuários tinham conhecimento para fazer desta forma.

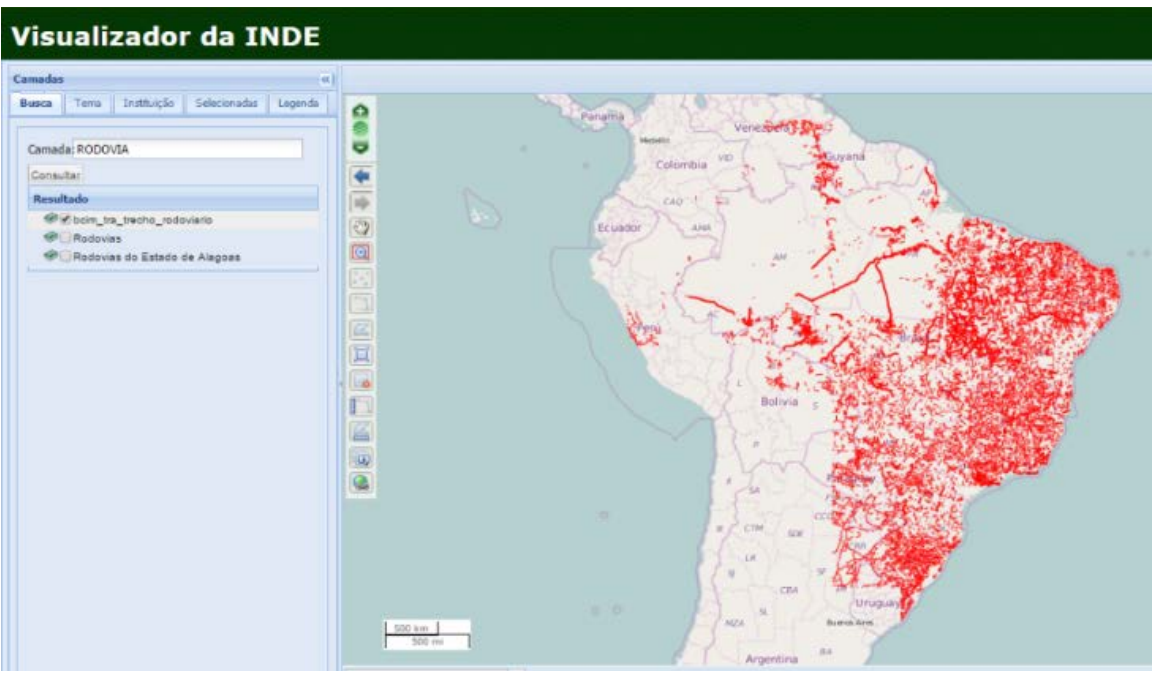

\section{Visualizador da INDE}

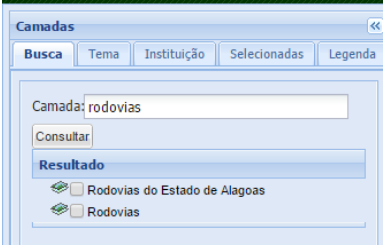

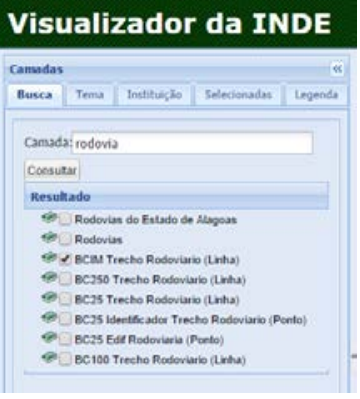

Figura 4. Camada Rede Viária Nacional - Rodovias carregada no VINDE e detalhes da busca por "Rodovia" e "Rodovias".

Fonte: <www.inde.gov.br>. 
Tarefa 3 - Buscar e ativar camadas ("Buscar e ativar a camada de Rede Viária Nacional - Rodovias”). Foi destacado pelos usuários que as camadas não têm nomes claros para o entendimento de qualquer pessoa, tanto na ferramenta de busca do VINDE como nas pesquisas nas abas "Temas" e "Instituições". É difícil se ter certeza, por exemplo, que as camadas "bcim_tra_trecho_rodoviário" ou "BC250 Trecho Rodoviário (Linha) ” carregam a camada da Malha Rodoviária Nacional ou Rodovias Nacionais. Além disso, as camadas não estão organizadas alfabeticamente, o que dificulta ainda mais a pesquisa. Esta tarefa teve o maior percentual de erros e tarefas incompletas (60\%), gastando $57,9 \%$ do tempo total disponível para executálas. Estes resultados devem-se principalmente ao fato de os usuários não correlacionarem o nome da camada solicitada (nome genérico) ao da camada existente. A ferramenta de busca também não ajudou. A Figura 4 mostra a camada correta de Rede Viária Nacional-Rodovias que deveria ter sido carregada assim como detalhes do não funcionamento da busca inteligente quando se digita "Rodovia" e "Rodovias", onde o resultado da busca deveria ser o mesmo e, como pode ser visto, isso não acontece.

Tarefa 4 - Visualizar camadas ("Visualizar um mapa que mostre as seguintes

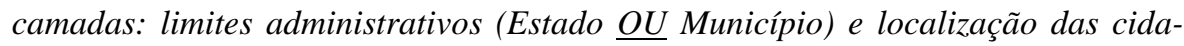
des"). As camadas de "Limite Estadual" e/ou "Limite Municipal” são encontradas dentro do Tema "Mapeamento Terrestre/Bases Contínuas", e não são encontradas dentro do Tema "Limites", opção de busca mais rápida e intuitiva. Também podem ser encontradas com o mesmo nome dentro da opção "Instituição" mas, para isso o usuário teria que ter o conhecimento de que esta informação é disponibilizadas pelo IBGE. Na ferramenta os nomes que carregam essas informações são: “bcim_lim_municipios” e "BC 250 Município (Polígono) ”, para municípios e "bcim_lim_unidade_federacao" e "BC 250 Unidade da Federação (Polígono) ", para estados. A camada com a sede das cidades não é encontrada dentro de "Localidades/Cidades”, e sim nas seguintes opções:

- Tema "Banco de Estruturas Territoriais", com o nome de "Sedes dos Municípios Brasileiros";

- Tema "Mapeamento Básico Terrestre/Bases Contínuas", com o nome de "bcim_loc_cidade";

- Tema "Mapeamento Básico Terrestre/Bases Contínuas", com o nome de "BC 250 Cidade (Ponto) ”.

Esta camada também pode ser encontrada na opção "Instituição" (IBGE) e na opção de "Busca", caso o usuário digite "Cidade".

Esta tarefa teve um percentual de erros e tarefas incompletas de $40 \%$, e um consumo de tempo de $67,4 \%$. 
De uma forma geral, por meio das atividades 3 e 4, pode-se observar que a ferramenta de busca não faz busca inteligente, não considerando singular e plural, por exemplo.

Tarefa 9 - Agregar WMS ("Agregar ao visualizador da IDE um serviço de mapas WMS (Web Map Service), através de consulta ao Geoserver”). Essa era a tarefa mais complexa da prova e, mesmo com a orientação dada por escrito com a seqüência a ser seguida e sites adicionais a serem consultados, os usuários se ressentiram da falta de um guia (passo-a-passo) no portal, assim como de links para acesso aos geosserviços existentes tanto da INDE quanto de outras instituições e empresas. Ainda que a prova tenha fornecido um endereço de geosserviços, ${ }^{5}$ a grande maioria dos usuários teve muita dificuldade de percorrer todo o caminho e concluir a tarefa. Observou-se que muitos não leram com atenção as orientações da tarefa, outros chegaram ao portal do Geoserver e se perderam por lá, outros avançaram bastante copiando o link do serviço mas não souberam o local certo de colá-lo no portal do VINDE. Esta tarefa também teve grande percentual de erros e tarefas incompletas, $40 \%$, e o maior tempo consumido, $69,5 \%$.

As demais tarefas eram relativas ao manuseio das ferramentas de manipulação e edição dos mapas. De forma geral, os usuários se queixaram da falta de explicações sobre a função de cada botão. À medida que se passava o cursor pelos ícones da tela, não apareciam as explicações de funcionalidade. Além disso, os usuários reclamaram do tamanho pequeno dos ícones destes botões - lembrando que a maioria dos usuários estava na faixa etária acima de 50 anos.

Para a análise de SUS foram aplicadas as fórmulas indicadas por Broke (1996) e obtenção da medida de satisfação. Como se observa nos resultados da Tabela 6, que contém as pontuações SUS por usuário, a maior medida de satisfação corresponde aos usuários 4 e 7 (88 pontos), enquanto a menor medida é relativa ao usuário 15 (20 pontos).

A média das pontuações SUS encontrada para a usabilidade total foi de 54.85, calculada a partir do software estatístico PSPP ${ }^{6}$. Ainda segundo Sauro e Lewis (2011), se considera que a pontuação média aceitável deve ser igual ou superior a 68. Para chegarem a este número, os especialistas promoveram cerca de quinhentos estudos. Uma pontuação acima de um SUS=68 seria considerada acima da média e qualquer valor abaixo de 68 é inferior à média. Sendo assim, a média SUS de 54.85 encontrada na prova é inferior à média. 
Tabela 6

Pontuações SUS por usuário

\begin{tabular}{cc}
\hline Usuários & Pontuações SUS \\
\hline Usuário 1 & 33 \\
Usuário 2 & 78 \\
Usuário 3 & 38 \\
Usuário 4 & 88 \\
Usuário 5 & 68 \\
Usuário 6 & 45 \\
Usuário 7 & 88 \\
Usuário 8 & 73 \\
Usuário 9 & 75 \\
Usuário 10 & 40 \\
\hline
\end{tabular}

\begin{tabular}{cc}
\hline Usuários & Pontuações SUS \\
\hline Usuário 11 & 58 \\
Usuário 12 & 23 \\
Usuário 13 & 48 \\
Usuário 14 & 53 \\
Usuário 15 & 20 \\
Usuário 16 & 53 \\
Usuário 17 & 43 \\
Usuário 18 & 65 \\
Usuário 19 & 65 \\
Usuário 20 & 43 \\
\hline
\end{tabular}

Fonte: elaboração própria.

\section{Conclusões}

Como resultado do processo de pesquisa, concluiu-se que o objetivo geral foi atingido a partir da obtenção dos objetivos específicos que foram definidos para a pesquisa por meio das atividades definidas na metodologia, ou seja:

Objetivo específico 1: foram identificar as principais metodologias para avaliação de usabilidade de geoportais;

Objetivo específico 2: foi elaborada uma metodologia para avaliar a usabilidade do visualizador de mapas do geoportal da INDE;

Objetivo específico 3: a metodologia foi devidamente validada através de uma prova piloto;

Objetivo específico 4: foi definida uma prova para avaliar a usabilidade;

Objetivo específico 5: a metodologia foi a um grupo de usuários.

A aplicação da metodologia demonstrou que, por meio da aplicação da prova de usabilidade, foi possível medir e avaliar a usabilidade do VINDE a fim de se identificar problemas e propor melhorias no seu conteúdo e layout.

O teste de desempenho que serviu para para medir a eficiência e eficácia mostrou que os usuários, mesmo com alguma dificuldade, tiveram uma média alta em relação ao número de tarefas realizadas corretamente (10,5 de 13) e, em tempo médio dentro do estabelecido (17:27 de 33:00). Entretanto, o resultado obtido para se medir a satisfação do usuário ficou abaixo do número aceitável na literatura acadêmica. (54,85 de 68). 
A prova de usabilidade, aplicada a uma amostra de vinte usuários, permitiu concluir que a importância da melhoria da usabilidade no VINDE se evidencia a partir dos seguintes aspectos:

- Identificou-se como preocupante que a informação, considerada como prioritária, não esteja claramente exposta na página principal de entrada, como é o caso do VINDE, onde o usuário tem que realizar previamente uma busca dentre uma enorme confusão de informações diversas. O visualizador é uma das partes mais importantes do geoportal, devendo, portanto, ser identificado de forma imediata para que $o$ acesso se faça com menos cliques. Recomenda-se que o VINDE esteja acessível com destaque e por meio de um único clique na página principal do geoportal.

- As ferramentas de manuseio precisam ser melhoradas em diversos aspectos: layout, descrição, funcionalidade, etc.

- Necessária melhoria da ferramenta de busca inteligente.

Além disso, apesar do objetivo da pesquisa ter sido a análise de usabilidade do VINDE observou-se problemas na organização e disposição dos dados no mesmo. Na verdade, as duas atividades onde essa questão era requisitada foram aquelas onde os usuários tiveram maior dificuldade, erros e insatisfação. Desta forma, recomenda-se que esse ponto seja estudado e revisto pelas instâncias responsáveis. O excesso de categorias e camadas dispostas sem organização lógica, não permitiram que nem quem tinha conhecimentos específicos em geoinformação achasse o que estava sendo pedido. Desta forma, recomenda-se que o número de categorias seja sensivelmente reduzido e que as camadas de informações, pastas principais e secundárias de temas sejam organizadas (principalmente com ordenação alfabética), agrupadas e que tenham seus nomes simplificados e padronizados. Essa nomenclatura precisa ser mais clara, com o objetivo de ser compreendida por qualquer usuário. Além disso, é importante se fazer realocação de determinadas camadas, como, por exemplo, "limites administrativos" (dentro do tema "limite") e "sedes municipais” (dentro do tema "localidades”). Recomenda-se também colocar o conteúdo de pastas de temas com seção órfã junto à seção anterior.

O presente artigo é parte da Dissertação de Mestrado da autora intitulada "Usabilidade de Geoportais: o caso do Visualizador da Infraestrutura Nacional de Dados Espaciais (INDE)", defendida em julho de 2016 no Instituto Militar de Engenharia, Curso de Engenharia de Defesa. 


\section{Referências}

Araújo, V. (2016). "Usabilidade de Geoportais: o caso do visualizador da Infraestrutura Nacional de Dados Espaciais (INDE) Tese de Mestrado, Instituto Militar de Engenharia, Rio de Janeiro, Brasil.

Araújo, V.O.H., de Carvalho Augusto, M.J., da Silva Py, H. e Oliveira (2015). R.A.A.C. The Usability of the National Spatial Data Infrastructure (INDE) Geoportal. 27th International Cartographic Conference, Rio de Janeiro.

Araújo, V.; Gonzalez, M.E. (2015). "Usabilidade do Visualizador da Infraestrutura Nacional de Dados Espaciais (VINDE), visão do usuário”, Revista Bahia Análise \& Dados, vol. 25, no. 4, trimestral, pp.753-772.

Bernabé-Poveda, M.A. y González, M.E. (2014). “Sobre la necesaria usabilidad de los geoportales como puertas de entrada a las IDE”, GeoFocus. Revista Internacional de Ciencia y Tecnología de la Información geográfica, núm. 14, pp. 1-5.

Brooke, J. (1996). "SUS-A quick and dirty usability scale", Usability evaluation in industry, vol. 189, no. 194, pp. 4-7.

Calderón, L.J.; Campoverde, J.Y. y Hoehne, A.V. (2014). "El usuario como factor de éxito en el diseño de un geoportal", Geofocus. Revista internacional de Ciencia y Tecnología de la información Geográfica, núm. 14, pp. 181-210.

CONCAR, Comissão Nacional de Cartografia (2010). Plano de Ação para Implantação da Infraestrutura Nacional de Dados Espaciais, Rio de Janeiro.

Herold, F.; Henzen, C. and Bernard, L. (2016). "Using Usability Test Results to create Usability Patterns for Geoportals” en He, X.; Persson, H.; Östman, A., Geoportal Usability Evaluation, International Journal Of Spatial Data Infrastructures Research. European Comission, 2012.

Gonzalez, M.E. et al. (2015). Proyecto Usabilidad de Geoportales IDE. Instituto Panamericano de Geografía e Historia, Programa de Asistencia Técnica, 2015. Disponible en <http://comisiones.ipgh.org/CARTOGRAFIA/PAT2015.html>.

ISO 9241-11 (1998). Ergonomic Requirements for Office Work with Visual Display Terminals (VDTs) -Part II Guidance on Usability.

Krug, S. (2006). Não me faça pensar!: uma abordagem de bom senso à usabilidade na web. F. Silveira (Ed.). Alta Books.

Maganto, A.S.; Pascual, A.P. and Bernabé, M.A. "Componentes de una IDE”, in Bernabé-Poveda, M.Á. and López-Vázquez, C.M. (2012). Fundamentos de las infraestructuras de datos espaciales (IDE), BibliotecaOnline SL, p. 65.

Maguire, D.J. and Longley, P.A. (2005). "The emergence of geoportals and their role in spatial data infrastructures", Computers, environment and urban systems, vol. 29, no. 1, pp. 3-14.

Nielsen, J. and Loranger, H. (2006). Prioritizing web usability, Pearson Education.

Nielsen, J. (2012). "How many test users in a usability study", Nielsen Norman Group, vol. 4, no. 6. 
Sanxiao, P. and Martines, G. (2012). La EIEL y los geoportales: cómo poner la información a disposición de la ciudadanía.

Sauro, J. (2011). Measuring usability with the system usability scale (SUS).

Sauro, J. and Lewis, J.R. (2011, May). When designing usability questionnaires, does it hurt to be positive?, in Proceedings of the SIGCHI Conference on $\mathrm{Hu}$ man Factors in Computing Systems ACM, pp. 2215-2224.

Open Geospatial Consortium, $<$ http://www.opengeospatial.org/domain/gov_and_sdi\#responsibility>. 